\section{EFFECTIVE INFORMATION CAMPAIGN FOR MANEAGEMENT OF EXPOSURE TO HAND-ARM VIBRATION}

${ }^{1}$ Riiltta Sauni, ${ }^{1}$ Pauliina Toivio, ${ }^{2}$ Esko Toppila, ${ }^{1}$ Rauno Pääkkönen, ${ }^{1,3}$ Jukka Uitti. ${ }^{1}$ Finnish Institute of Occupational Health, Tampere, Finland; ${ }^{2}$ Finnish Institute of Occupational Health, Helsinki, Finland; ${ }^{3}$ Clinic of Occupational Medicine, Tampere University Hospital, Tampere, Finland

\subsection{6/injuryprev-2016-042156.1041}

Background European Directive 2002/44/EC defines employers' responsibilities in the risk management of hand-arm vibration (HAV). However, the directive is still not completely implemented in all risk industries.

Methods The aim of our study was to determine whether it is possible to improve the recognition and management of the risks of HAV at workplaces with a one-year information campaign. A questionnaire on opinions and measures for controlling HAV exposure at workplaces was sent to all occupational safety representatives and occupational safety managers in the construction and metal industry in Finland $(\mathrm{n}=1887)$ and once again to those who responded to the first questionnaire $(n=961)$ one year after the campaign.

Results The campaign increased recognition of HAV in risk assessment from $57.0 \%$ to $68.3 \%(\mathrm{p}=0.001)$, increased measures to decrease exposure to HAV from $54.6 \%$ to $64.2 \%$ $(\mathrm{p}=0.006)$, and increased the number of programmes to control the risks due to HAV ( $\mathrm{p}<0.001$ ).

Conclusions The information campaign, which focuses on the construction and metal industries, proved to be effective in increasing the awareness of the risks of HAV and the measures needed to control exposure to HAV. A similar campaign can be recommended in the case of risks specific to certain occupations.

\section{SAFETY CARD TRAINING FOR SOCIAL AND HEALTH SERVICES}

Camilla Volanen. The Finnish Association of Fire Officers, Finland

\subsection{6/injuryprev-2016-042156.1042}

Background First Safety forum for social and health services was organised in 2005. It brought together safety authorities and professionals in social and health services to discuss safety issues. The forum awoke need for national safety training for social and health services. The Finnish Association of Fire Officers started developing Safety card training for social and health services immediately and first trainings were held in 2006.

Board for safety in social and health services develops the training material constantly. President of the board is safety manager Anna Tamminen from the Joint Municipal Authority of the Pirkanmaa Hospital District. The board also has members from:

- The Finnish Association of Fire Officers

- The Finnish National Rescue Association SPEK

- Ministry of Social Affairs and Health

- National Institute for Health and Welfare

- rescue departments

- The Finnish Union of Practical Nurses SuPer

- Tehy - The Union of Health and Social Care Professionals in Finland

- the Association of Finnish Local and Regional Authorities

Methods The Safety card training for social and health services is meant for all employees and students in social and health services. It gives the employee tools for accident prevention and how to act in a case of an emergency. Duration of the training is one day and people who have completed the course receive a certificate card that is valid for five years. The training emphasises role of employee in risk prevention and includes theory, group work and optional practical exercise.

Results Safety card training for social and health services has been regarded very good training and you can emphasise different things depending on the target group. It is a basic safety training which guarantees employers certain basic level of safety training. There are nearly 30.000 people who have taken the safety card training.

Conclusions Safety of the social and health services should still be developed and the training material should be updated according to needs from the field. National safety training should be adopted even more widely and it should be a mandatory part of education in social and health services. There could also be international potential in safety card concept.

\section{THE DISTRICT LEVEL -ROAD TRAFFIC ACCIDENT INVESTIGATION TEAM DEVELOPMENT FOR SOLVING PROBLEM SYSTEM IN 9 TH REGIONAL HEALTH OFFICE, THAILAND, 2013 - 2014}

Kanjana Yangkao, Kanyarat Srakaew. The Office of Disease Prevention and Control 9 ,Th Nakhonratchasima Province, Thailand

\subsection{6/injuryprev-2016-042156.1043}

Background In 2013, Thailand ranked the world's third in highest road fatalities.To solve the problem, A data collection should be collected systematically including person, place, time, risk behaviour, risk factor and process of working. So, a development program should be held in order to enhance investigation and data analysis skills for creating specific measures.

Methods This project was purpose for enhancing the team investigation-skill efficiency in order to solve the road traffic accident problem by using the investigated data. The action research is used for developing the mutidisciplinary field road traffic investigation teams. The program is provided in 46 district in $9^{\text {th }}$ Regional Health Office from October 2013 to September 2014.

Results Two teams from 46 teams can create two specific measures, Firstly the 97 community checkpoints manage by the villagers at Phutthaisong district in Burirum province. In Songkran festival 2014, They prohibited 325 drunken villagers from driving. The result showed that the injury from road traffic accidents decrease $72 \%$ from last year.The other measure is rest area on main road in order to prevent drawsy driving by network cooperation at Kaengkhro district in Chaiyaphum province.

Conclusions As the result of the project every district should have the road traffic accident investigation with intensively training to analyse the data, investigate the cause of accident and suggest the way to solve problem to the related local government office.

\section{COLLECTING LEISURE TIME ACCIDENT INFORMATION FROM EMPLOYEES}

Toni Hyytinen, Jouni Kivistö-Rahnasto. Tampere University of Technology

10.1136/injuryprev-2016-042156.1044 